Research Article

\title{
Strength Weakening Effect of High Prestatically Loaded Marble Subjected to Low-Frequency Dynamic Disturbance under Point Load
}

\author{
Wuxing Wu $\mathbb{D}^{1,2}$ and Fengqiang Gong $\mathbb{D}^{1,2}$ \\ ${ }^{1}$ Engineering Research Center of Safety and Protection of Explosion \& Impact of Ministry of Education (ERCSPEIME), \\ Southeast University, Nanjing 211189, China \\ ${ }^{2}$ School of Civil Engineering, Southeast University, Nanjing 211189, China
}

Correspondence should be addressed to Fengqiang Gong; fengqiangg@126.com

Received 1 March 2021; Accepted 19 May 2021; Published 28 May 2021

Academic Editor: Nan Jiang

Copyright (c) 2021 Wuxing Wu and Fengqiang Gong. This is an open access article distributed under the Creative Commons Attribution License, which permits unrestricted use, distribution, and reproduction in any medium, provided the original work is properly cited.

\begin{abstract}
The deep high prestatically loaded rock is often subjected to low-frequency dynamic disturbance and exhibits unusual strength characteristics, and thus, it is important to investigate the strength characteristics under the coupling effect of prestatic load and low-frequency dynamic disturbance loading conditions. In this study, a series of point load tests were conducted on the high prestatically loaded marble subjected to low-frequency disturbance by the MTS system, focusing on exploring the role of prestatic load level and low-frequency disturbance frequency in the process of rock strength change. Based on the average static failure load $\left(F_{\max }\right)$ of samples under the static point loading, the high prestatic load levels $\left(F_{p}\right)$ were selected as $70 \%, 80 \%$, and $90 \%$ of $F_{\max }$, the corresponding low-frequency dynamic disturbance was loaded by sinusoidal waves with amplitudes of $60 \%, 40 \%$, and $20 \%$ of $F_{\max }$, and the low-frequency dynamic disturbance frequencies $(f)$ are $1,2,5$, and $10 \mathrm{~Hz}$. The change curve of the point load strength with the prestatic load level or the disturbance frequency was analyzed, which indicates that the point load strength under the coupled high prestatic load and low-frequency dynamic disturbance load was significantly lower than that under the pure static loading, presenting a significant point load strength weakening effect. Only when $F_{p}$ or $f$ reaches a certain level, the point load strength decreases significantly as $f$ or $F_{p}$ increases. Moreover, the point load strength weakening rate was proposed to characterize the degree of strength weakening. The comprehensive analysis demonstrates that $F_{p}$ has a greater effect on the point load strength weakening effect than $f$, which is mainly reflected in the point load strength weakening level dominated by the $F_{p}$, and the weakening degree is affected by $f$.
\end{abstract}

\section{Introduction}

With the decrease of shallow mineral resources and the increasing demand for underground space, more and more underground projects extend to great depth. The deep surrounding rock has been subjected to high static stress before excavation $[1-3]$ and then undergoes various forms of dynamic disturbance during the excavation process $[4,5]$, resulting in the high static load surrounding rock in a stress state coupled with high static load and dynamic disturbance load. For instance, Li et al. [2,6] pointed out the deep high prestatically loaded rock often affected by the dynamic disturbance and developed the split Hopkinson pressure bar (SHPB) test device to deeply study the mechanical characteristics and failure mechanism of rock under static and dynamic combined loading. Zhang and Zhao [7] summarized the research of rock dynamic mechanics in detail and reported that the high prestatic rocks are often affected by dynamic disturbances during, before, and after the exaction process. Liu et al. [8] pointed out in detail that the high prestressed rock is in the coupled static-dynamic stress state during deep rock engineering excavation. Ernesto et al. [9] analyzed the deep high prestatic rock failure under deep engineering excavation and estimated the probability of 
static and dynamic demand for rock mass stable in underground excavation. These studies have clearly pointed out that the deep high prestatically loaded surrounding rock is often subjected to dynamic disturbance, under the coupling stress state of the high prestatic load and dynamic disturbance. Moreover, compared with pure static or pure dynamic stress state, the failure characteristics of the deep high prestatically loaded surrounding rock under the dynamic disturbance are obviously different, which cannot be explained reasonably by traditional rock mechanics theory $[2,6]$. Therefore, knowledge of the high prestatically loaded rock subjected to dynamic disturbance on deep rock fracture characteristics and mechanical behaviors has significance for the construction of deep underground rock engineering.

To date, researchers have conducted a lot of experimental and theoretical studies to understand the fracture behavior and mechanism of high prestatically loaded rock. Gao et al. [10] studied the effect of dynamic loading rate on the development of cracks in the process of deep rock failure and obtained the fractal dimension change characteristics of the dynamic fracture of the sample under impact load with different loading rates. Vaneghi et al. $[11,12]$ carried out a large number of uniaxial cyclic loading-unloading tests on deep rocks and investigated the influence of different loading and unloading conditions on the failure characteristics of deep rocks. Moreover, in order to better fit the stress state of deep rock failure, a large number of impact tests under high prestatic rock were also carried out. Li et al. [2] concluded that the dynamic compressive strength of siltstone firstly increased and reached a maximum constant value under the constant axial precompression stress and increased impact load. Gong et al. [13] conducted a one-dimensional coupled static-dynamic loading test on red sandstone and obtained that the impact compression strength of the rock reached the maximum value if the axial precompressive stress ratio was 0.6 to 0.7 . Zhou et al. [14] used the modified SHPB to carry out impact tests of sandstone with the axial static prestresses of $0 \sim 75 \mathrm{MPa}$, and the results showed that the dynamic compressive strength increases with the prestress until it reaches $75 \mathrm{MPa}$. Zhu et al. [15] used the numerical simulation methods to discuss in detail the effect of the coupled static-dynamic loads on the compression failure characteristics of rocks. These results enrich the failure characteristics of the one-dimensional high prestatic rock subjected to the strong impact dynamic disturbance. Additionally, the deep rock subjected to the impact dynamic disturbance under different confining pressures on deep rock compressive failure was also carried out. Peng et al. [16] used the SHPB to carry out dynamic impact tests under different confining pressures and reported that the rock only shows shear failure as the confining pressure limits the lateral deformation. Yin et al. [17] and $\mathrm{Ma}$ et al. [18] investigated the failure characteristic under the rock was in a state of confining pressure after excavation and conducted a dynamic compressive test of the rock under confining pressure by the SHPB. Liu et al. [19] used the triaxial Hopkinson bar and investigated the dynamic compressive characteristics of sandstone under biaxial compression. Yuan et al. [20] conducted a numerical simulation to study the dynamic failure characteristics of rock under confining pressure. $\mathrm{Hu}$ et al. [21] used the finite element to simulate dynamic impact tests under different multiaxial static loads on rocks and explored the influence of prestatic load and dynamic impact on rock failure. With the improvement of the understanding of rock failure, people not only carry out the above compression tests but also deeply explore the characteristics of rock failure such as tension and fracture. Zhu and Tang [22] and $\mathrm{Wu}$ et al. [23] explored the tensile failure characteristics of rocks subjected to the coupled high prestatic load and impact dynamic loads. Moreover, Yao et al. [24], Chen et al. [25], and Shi and Chen [26] investigated the fracture failure characteristics of the prestatically loaded rock subjected to dynamic loads.

However, the above research on rock fracture failure subjected to coupled high prestatic load and dynamic load is mainly based on strong impact dynamic disturbance load, rarely involving low-frequency dynamic disturbance. Su et al. [27] reported that, in the process of deep rock engineering excavation, the surrounding rock was often affected by low-frequency dynamic disturbance, which poses a threat to underground engineering construction. However, these studies have not focused on the rock strength variation characteristics under the low-frequency disturbance, especially the strength characteristics of high prestatically loaded rock under low-frequency disturbance. Therefore, it is necessary to research the prestatically loaded rock subjected to the low-frequency dynamic disturbance, especially for point load on the deep rock fracture subjected to coupled high prestatic load and low-frequency dynamic load. In essence, the deep rock is always under high prestatic load, and then it is affected by various dynamic disturbances, which induces the deep rock failure. From this point of view, this paper carried out a point load test in which the high prestatic rock was subjected to low-frequency dynamic disturbance to study the strength characteristics of the rock under this stress state, that is, the corresponding prestatic load is applied to the rock first, and then the low-frequency dynamic disturbance is applied until failure.

To further study the rock fracture characteristics of high preloaded rock subjected to low-frequency dynamic disturbance, a series of point load tests under these coupled load conditions were designed. In our study, the sum of all prestatic load levels and the corresponding one-half of the dynamic disturbance amplitude is equal to the average failure load $\left(F_{\max }\right)$ under the static point load tests (i.e., the $\left.F_{p}+0.5 F_{d}=F_{\max }\right)$. Therefore, the prestatic load levels $\left(F_{p}\right)$ were set to $70 \%, 80 \%$, and $90 \%$ of $F_{\max }$, while the corresponding low-frequency dynamic disturbance amplitudes $\left(F_{d}\right)$ were set as $60 \%, 40 \%$, and $20 \%$ of $F_{\text {max }}$. Moreover, a sinusoidal disturbance wave at low-frequency dynamic disturbance frequencies $(f)$ of $1,2,5$, and $10 \mathrm{~Hz}$ was selected. It is hoped that these coupled static and dynamic loading tests can be designed to study the failure characteristics of rock under low-frequency dynamic disturbance rather than the existing strong impact disturbance. The resulting variations in point load strength were obtained, and the obvious weakening effect of point load strength was found. Furthermore, through the load-deformation curve, the variation 
of the point load strength with $F_{p}$ and $f$, the rock failure mechanism in the point load test under coupled static-dynamic loading was obtained.

\section{Experimental Plans}

2.1. Sample Preparation. The rock samples selected in the all point load tests were obtained from the marble blocks in Hezhou City (Guangxi Province, China) as it has good homogeneity. Petrographic thin section analysis indicates that the marble is fine-grained and well sorted, which is mainly composed of quartz (99\%), and the matrix material composed of clay is about $1 \%$ of the sample [28]. The micrograph from the marble samples and the composition content are illustrated in Figure 1.

For the marble preparation for the point load tests, the whole marble rock block was made into cylindrical samples of $50 \times 50 \mathrm{~mm}^{2}$ (i.e., the ratio of the diameter $(D)$ to the length $(L)$ of the sample is 1$)$. A series of screening and polishing procedures (such as measuring scale, weighing, measuring wave velocity, and sandpaper grinding) were conducted on cylindrical samples to make the sample size accuracy meet the requirements suggested by ISRM (International Society of Rock Mechanics) [29], thereby reducing the test errors (as shown in Figure 2). The prepared marble samples have the following physical and mechanical properties: density was $4272 \mathrm{~kg} / \mathrm{m}^{3}, P$-wave velocity was $2.69 \mathrm{~km} / \mathrm{s}$, and the UCS (average uniaxial compressive strength) was $54.84 \mathrm{MPa}$ [28].

2.2. Test Equipment. The axial point load tests of the prestatically loaded marble subjected to low-frequency dynamic disturbance were conducted on the MTS Landmark servocontrolled testing system, as illustrated in Figure 3. This MTS Landmark test system is mainly composed of hydraulic test equipment and control software, which can perform static, dynamic, or coupled static-dynamic loading tests. The equipment can withstand the maximum dynamic load of $\pm 100 \mathrm{kN}$ and provide sine waves, triangle waves, and ramp waves with the disturbance frequency between 0 and $100 \mathrm{~Hz}$ as dynamic disturbance loads. The control software automatically collects the axial load and displacement changes during the whole process of loading the sample. Moreover, two special loading cones were machined according to the ISRM recommendations on the point load strength measurement method [29].

\subsection{Experimental Procedures}

2.3.1. Point Load Test under Static Loading. To obtain the relevant parameters of the point load test under the prestatically loaded marble subjected to low-frequency dynamic disturbance, the point load test under the static load was first carried out. The specific test process is as follows: (1) the cylindrical end of the loading cone was put into the clamping groove of MTS Landmark and the clamping force was adjusted to fix it; (2) the test piece was placed between the two pressure cones, and the loading cone was aligned at the center of the sample section; (3) after the sample was placed, a load of $0.5 \mathrm{kN}$ was preapplied to fix it. In the static loading process, the sample was loaded at $5 \mathrm{kN} / \mathrm{min}$ until the sample was damaged. The calculation formula of the point load strength is given by [29]

$$
I_{s}=\frac{F}{D_{e}^{2}},
$$

where $I_{s}$ is the point load strength (MPa), $F$ is the failure load $(\mathrm{N})$, and $D_{e}$ is the "equivalent core diameter" $(\mathrm{mm})$ [29]. For the axial point load test, $D_{e}^{2}=(4 A / \pi)$, and $A=W D=$ minimum cross-sectional area of a plane through the platen contact points [29].

Table 1 shows the static point load test results. The failure load under static loading of the sample is 6.44, 6.48, and $6.61 \mathrm{kN}$, the average failure load is $6.51 \mathrm{kN}$ (i.e., $F_{\max }=6.51 \mathrm{kN}, F_{\max }$ represents the maximum failure load), and the standard deviation is $2 \%$, indicating that the sample has good homogeneity. Based on equation (1), the point load strength of the marble sample is $2.03 \mathrm{MPa}$ (i.e., $I_{s}^{s}=2.03 \mathrm{MPa}$ represents the average point load strength under static loading). Figure 4 represents the load-displacement curves and the typical point load failure mode of the samples under the static point load. The variation characteristics of the load-displacement curves of the three marble samples are basically the same, and the curve S-3 may be deviated due to the difference in the homogeneity of the sample. Moreover, the sample fractures into two approximately symmetrical halves at the axial centerline under the static point load loading.

\subsubsection{Point Load Test on Prestatically Loaded Marble Sub-} jected to Low-Frequency Dynamic Disturbance. In the prestatically loaded marble subjected to dynamic disturbance test, the marble samples were first loaded to the prestatic load level $\left(F_{P}\right)$ at the loading speed of $5 \mathrm{kN} / \mathrm{min}$ under the static loading, and then the sine-wave load with a specific low-frequency disturbance frequency $(f)$ and disturbance amplitude $\left(F_{d}\right)$ was applied, as represented in Figure 5. Based on the static point load test, the corresponding dynamic disturbance parameters are determined. The prestatic load levels are set to $70 \%, 80 \%$, and $90 \%$ of $F_{\max }$ (i.e., $4.65,5.21$, and $5.86 \mathrm{kN}$ ), the corresponding low-frequency dynamic disturbance amplitudes are $60 \%, 40 \%$, and $20 \%$ of $F_{\max }\left(F_{d}=F_{\max }-F_{\min }\right.$, where $F_{\max }$ and $F_{\min }$ are the maximum and minimum disturbance loads), and the lowfrequency dynamic disturbance frequency is $1,2,5$, and $10 \mathrm{~Hz}$.

\section{Results and Discussion}

3.1. Overall Load-Deformation Behavior. After processing the load and displacement data of all prestatically loaded marbles subjected to low-frequency dynamic disturbance, some typical load-displacement curves are obtained as illustrated in Figure 6. Compared with the static point load tests, the load-displacement curve of the prestatically loaded sample subjected to the low-frequency dynamic disturbance 


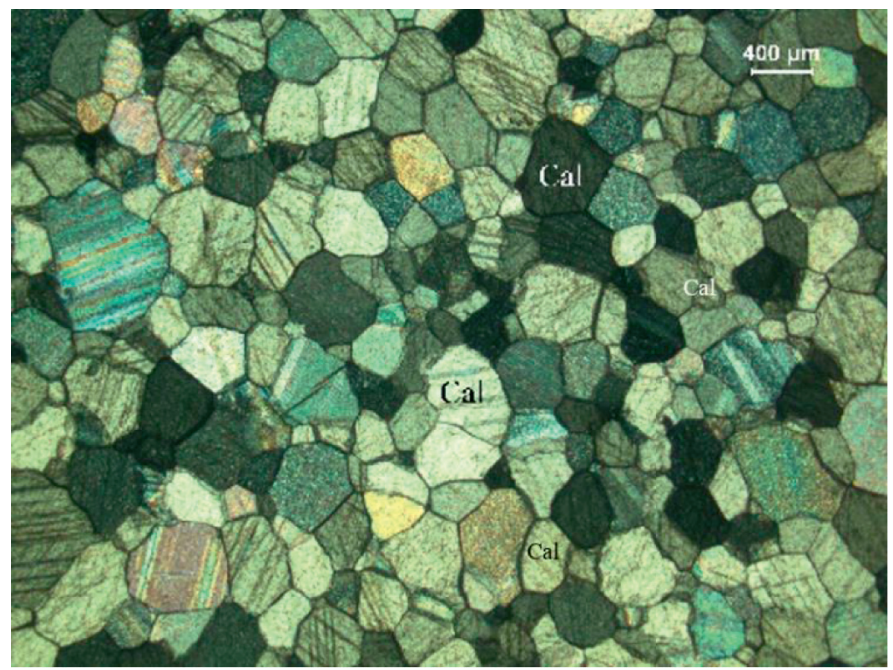

(a)

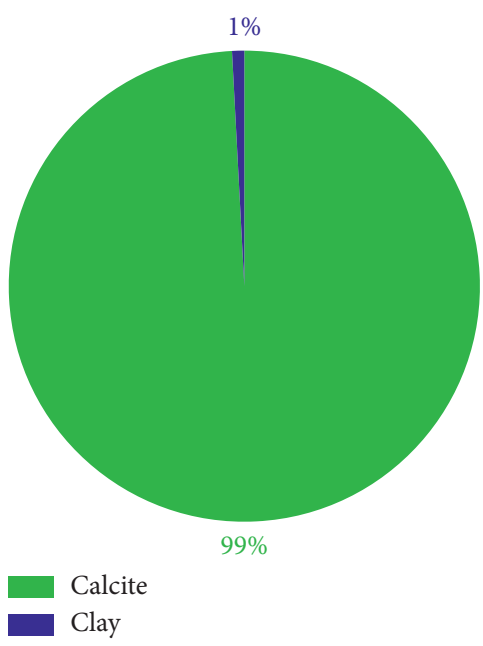

(b)

FIgure 1: Photomicrographs of marble samples. (a) Single polarization (Cal=calcite) [28]. (b) Composition content.

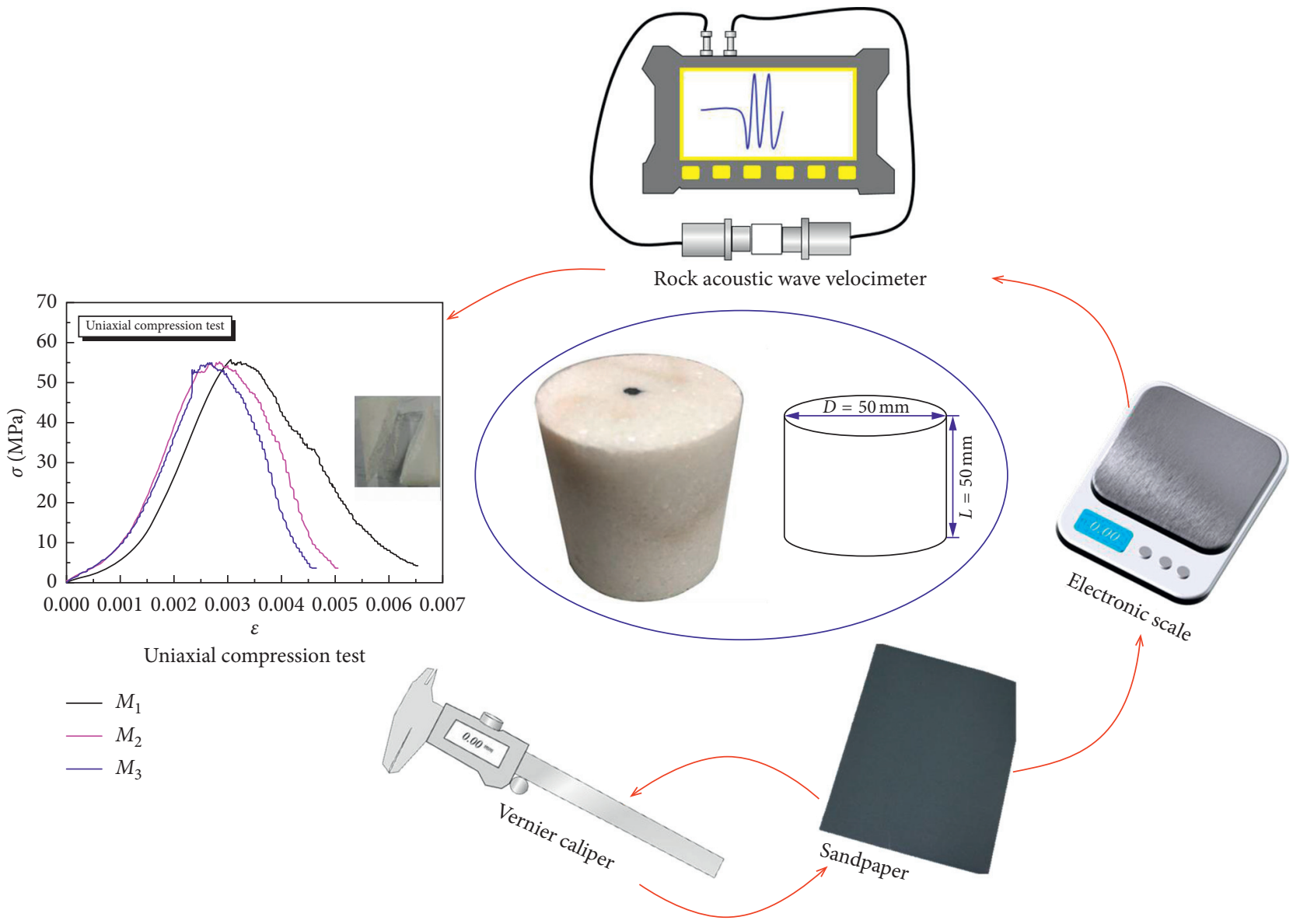

FIgURE 2: Marble sample processing process.

presents an obvious hysteretic loop and even an obvious sparse density-sparse evolution law. Additionally, when the sample was subjected to disturbance loading to the maximum failure load for the first time from the prestatic load level, the axial deformation develops faster, indicating that the rock has large deformation and generated initial cracks. Subsequently, the deformation curve develops as a dense hysteretic loop with the development of the dynamic disturbance process, indicating that the internal cracks continued to develop and penetrate until the rock failure. Table 2 


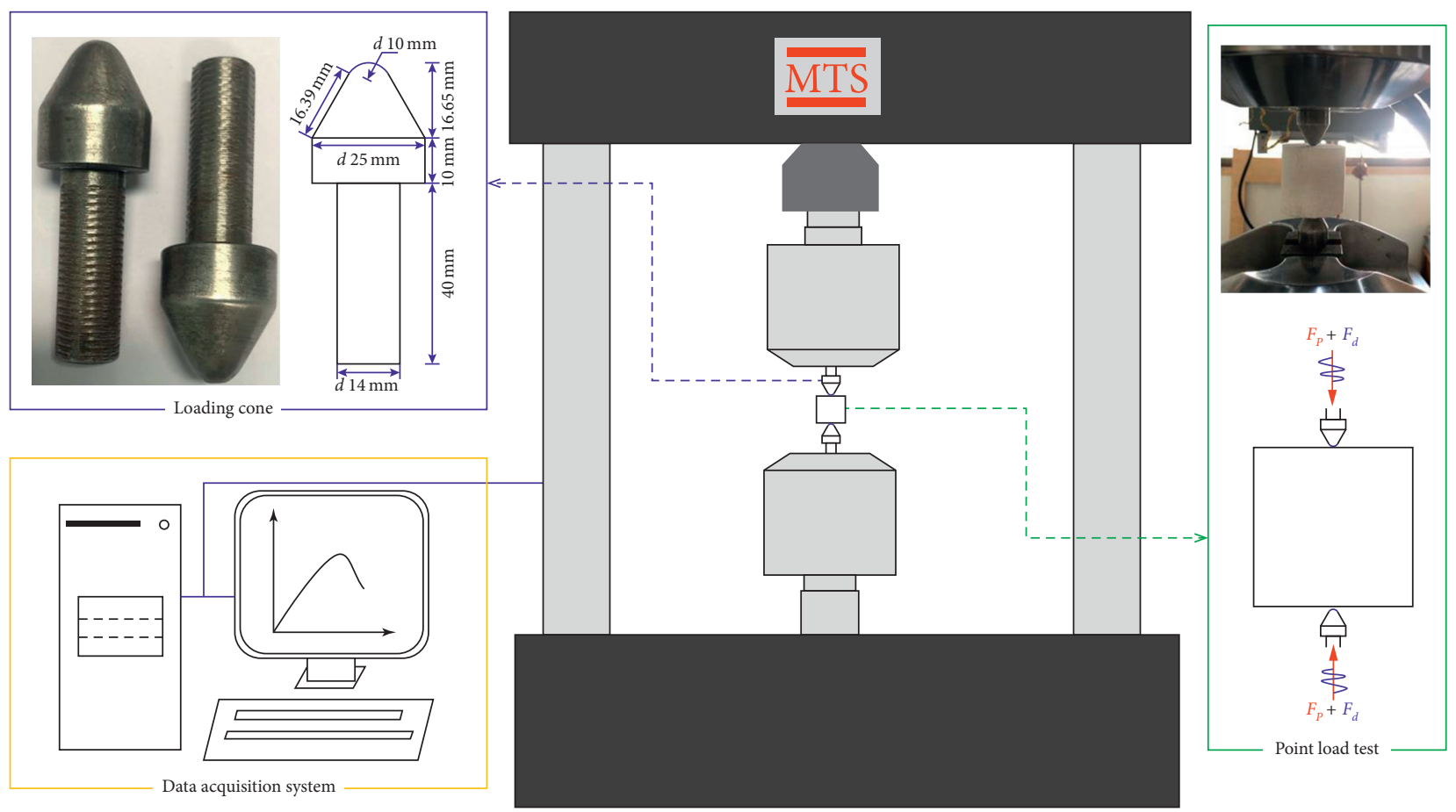

Figure 3: Test equipment.

TABLE 1: Point load test results under static load.

\begin{tabular}{lcc}
\hline Sample & $F(\mathrm{kN})$ & $I_{s}(\mathrm{MPa})$ \\
\hline S-1 & 6.44 & 2.01 \\
S-2 & 6.48 & 2.03 \\
S-3 & 6.61 & 2.07 \\
Average & 6.51 & 2.03 \\
\hline
\end{tabular}

and Figure 7 summarize the failure loads of all prestatically loaded marble samples subjected to low-frequency dynamic disturbance. Obviously, the failure loads of all marble under the prestatic load and low-frequency dynamic coupling are significantly lower than that under static point load tests. For instance, if $F_{P}$ is $80 \%$ of $F_{\max }$, the maximum failure load that the sample can withstand at $f=5 \mathrm{~Hz}$ is $6.21 \mathrm{kN}$, which is lower than the maximum failure load of $6.51 \mathrm{kN}$ under the static loading, and similar trends can be found in other load conditions. Furthermore, the failure load continuously decreases with the increase of $f$, indicating a significant strength weakening trend (Figure 7). As a result, the corresponding point load strength will inevitably gradually decrease as the failure load decreases. Therefore, the influences of $F_{P}$ and $f$ on the point load strength weakening are discussed hereafter.

\subsection{The Influence of $F_{P}$ on the Point Load Strength Weakening} Effect. The failure loads in the point load test of the prestatically loaded marble subjected to low-frequency dynamic disturbance are significantly lower than that under the static point load test (Figure 7), and the corresponding point load strength will also change. Therefore, the corresponding point load strength is calculated based on equation (1), as presented in Table 3. Clearly, the point load strength of the prestatically loaded marble under low-frequency dynamic disturbance is lower than that under static loading, and it also shows obvious strength weakening. For instance, if $F_{P}$ is $70 \%$ of $F_{\max }$, the point load strength of the sample at $f=10 \mathrm{~Hz}$ is $1.91 \mathrm{MPa}$, which is lower than $2.03 \mathrm{MPa}$ under the static loading. Similarly, when $F_{P}$ is $90 \%$ of $F_{\max }$, the point load strength of the sample is $1.87 \mathrm{MPa}$ at $f=10 \mathrm{~Hz}$, which is also significantly lower than $I_{s}^{s}$, and similar trends can be found in other load conditions. This comparison suggests that the prestatically loaded marble subjected to low-frequency dynamic disturbance significantly weakens the point load strength, showing obvious strength weakening effect.

Therefore, to quantitatively analyze the point load strength weakening effect, the point load strength weakening rate (PSWR) is proposed as follows:

$$
\operatorname{PSWR}=\frac{I_{s}^{s}-I_{s}^{d}}{I_{s}^{s}} \times 100 \%,
$$

where $I_{s}^{s}$ is the average static point load strength under the static loading test and $I_{s}^{d}$ is the point load strength of prestatically loaded marble samples subjected to low-frequency dynamic disturbances.

Figure 8 presents the change in point load strength and the PSWR of the prestatically loaded marble samples as the disturbance frequency increases. Clearly, no matter what $F_{P}$ and $f$ are, the point load strength of the prestatically loaded marble subjected to low-frequency dynamic disturbance is obviously lower than that under the static loading. Moreover, the point load strength gradually decreases with the increase of $f$ under the same $F_{P}$, which indicates that the 


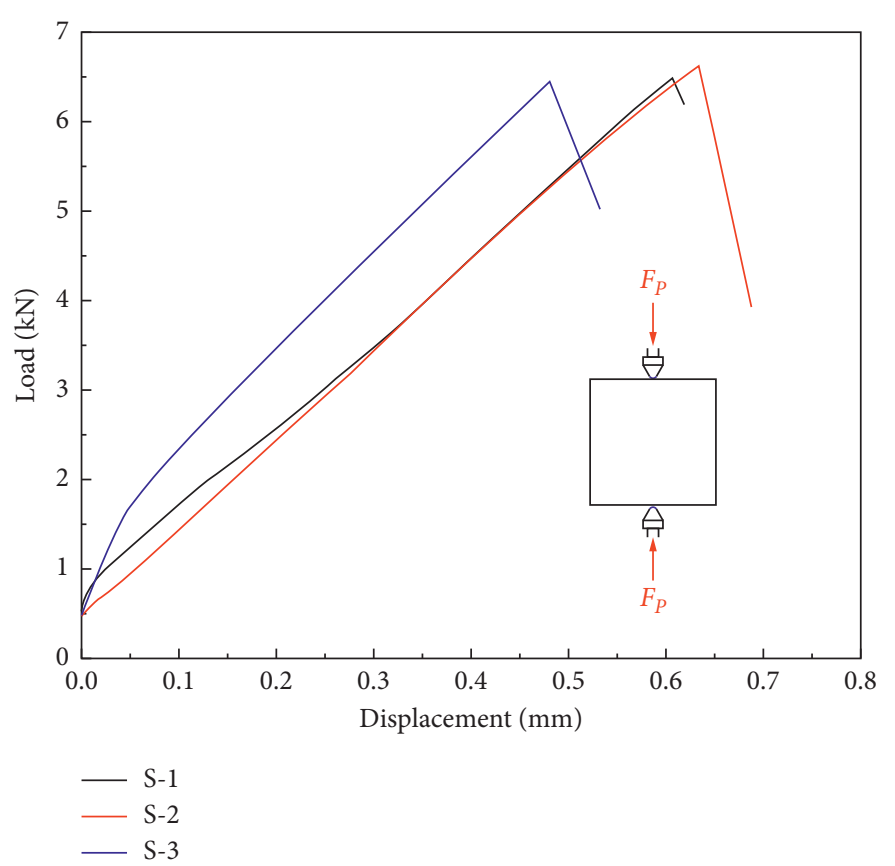

(a)

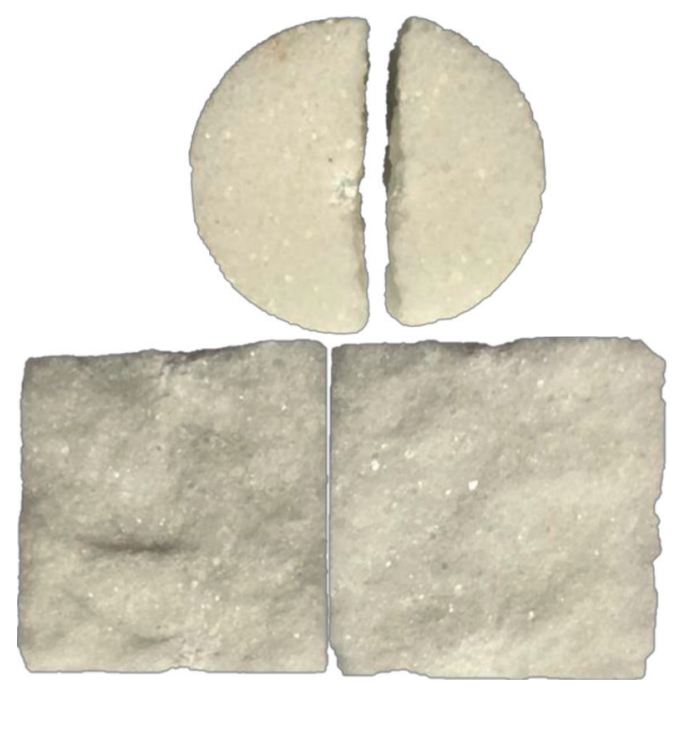

(b)

Figure 4: Point load test under static load. (a) Load-displacement curve. (b) Failure mode.

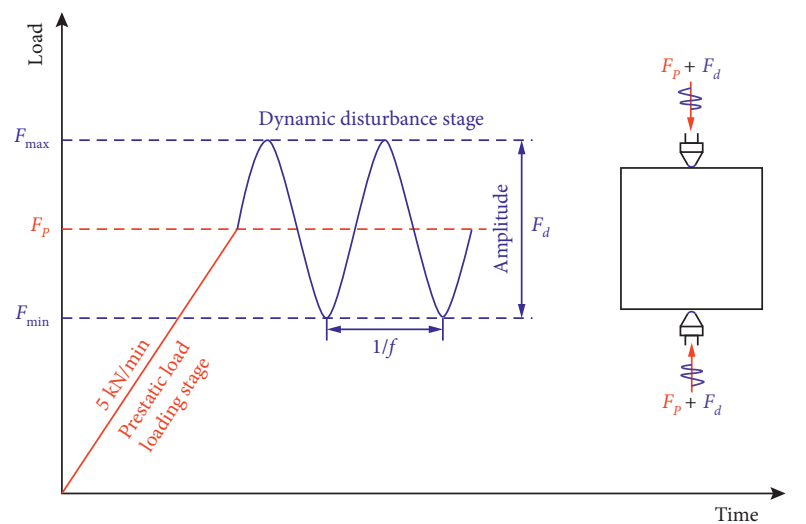

Figure 5: Point load test loading path of prestatically loaded marble subjected to low-frequency dynamic disturbance.

point load strength has obvious strength weakening effect. As shown, if $F_{P}$ is $70 \%$ of $F_{\max }$, the point load strength gradually decreases from $2.03 \mathrm{MPa}$ under static loading to $1.99 \mathrm{MPa}$ at $f=1 \mathrm{~Hz}$, and the lowest is as low as $1.91 \mathrm{MPa}$ under $f=10 \mathrm{~Hz}$, with a maximum reduction of $6.20 \%$. Similar trends can also be found at other prestatic load levels, for example, the reduction range of point load strength is $1.96 \sim 1.90 \mathrm{MPa}$ at $80 \%$ of $F_{\max }$ and $1.95 \sim 1.87 \mathrm{MPa}$ at $90 \%$ of $F_{\text {max }}$. These results imply that increasing $f$ can promote the point load strength weakening and affect the strength weakening degree. Furthermore, the higher the $F_{P}$, the point load strength weakening effect is more significant at the high frequencies. For instance, when $F_{P}$ is $80 \%$ of $F_{\text {max }}$, the PSWR is between $3.57 \%$ and $6.51 \%$, while if $F_{P}$ is $90 \%$ of $F_{\max }$, the PSWR is between $4.32 \%$ and $8.00 \%$, which is much larger than that of other prestatic load levels. These results strongly demonstrate that $F_{P}$ is dominant in the point load strength weakening process, that is, the $F_{P}$ determines its strength weakening level.

3.3. The Influence of $f$ on Weakening Point Load Strength. Figure 9 presents the change in point load strength and the PSWR of prestatically loaded marble samples as the prestatic load level increases. Clearly, the point load strength gradually decreases due to the increase in $F_{P}$ under the same $f$. Obviously, if $f=1 \mathrm{~Hz}$, the point load strength decreases from $1.99 \mathrm{MPa}$ at the $70 \%$ of $F_{\max }$ to $1.96 \mathrm{MPa}$ at the $80 \%$ of $F_{\max }$ as the $F_{P}$ increases, until the maximum decreases to $1.95 \mathrm{MPa}$ at $90 \%$ of $F_{\max }$, and similar trends can also be observed at other disturbance frequencies. Moreover, $F_{P}$ promotes the point load strength weakening more significantly at high disturbance frequencies. As shown, when $f=2 \mathrm{~Hz}$, the point load strength decreases from $2.03 \mathrm{MPa}$ under the static load to $1.94 \mathrm{MPa}$ at $90 \%$ of $F_{\max }$, and the PSWR can reach up to $4.71 \%$. However, if $f$ increases to $10 \mathrm{~Hz}$, the point load strength maximum decreases to 1.87 $\mathrm{MPa}$ with the increase of the $F_{P}$, and the PSWR is as high as $8.00 \%$, which is much higher than the decrease at other disturbance frequencies. Furthermore, the interval between the disturbance frequency between $5 \mathrm{~Hz}$ and $10 \mathrm{~Hz}$ is much larger than the interval between other disturbance frequencies, which implies that increasing $F_{P}$ can obviously promote the point load strength weakening if $f$ reaches a value.

3.4. Point Load Strength Weakening Mechanism Analysis. These experiments indicated that, in the point load tests of the kind of high preloaded rock subjected to low-frequency 


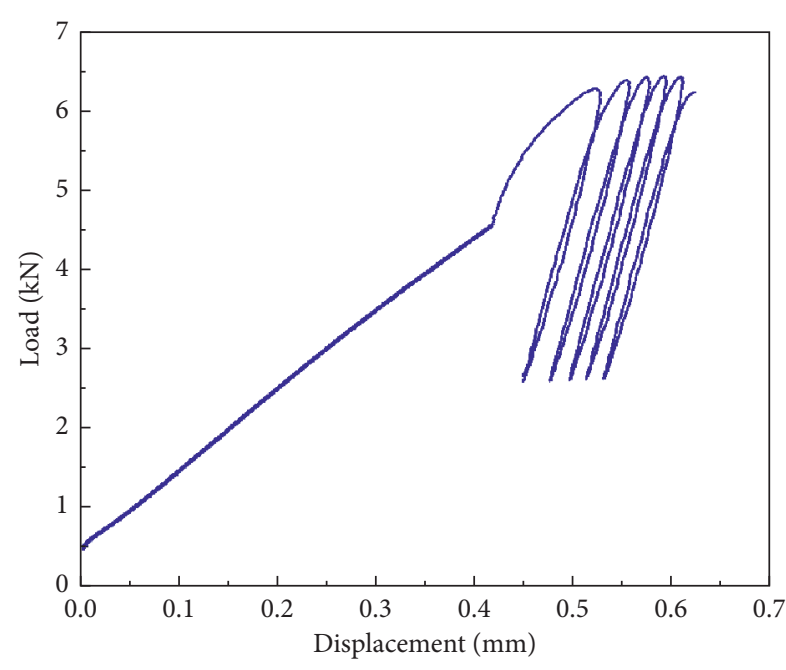

$-70 \%-5 \mathrm{~Hz}$

(a)

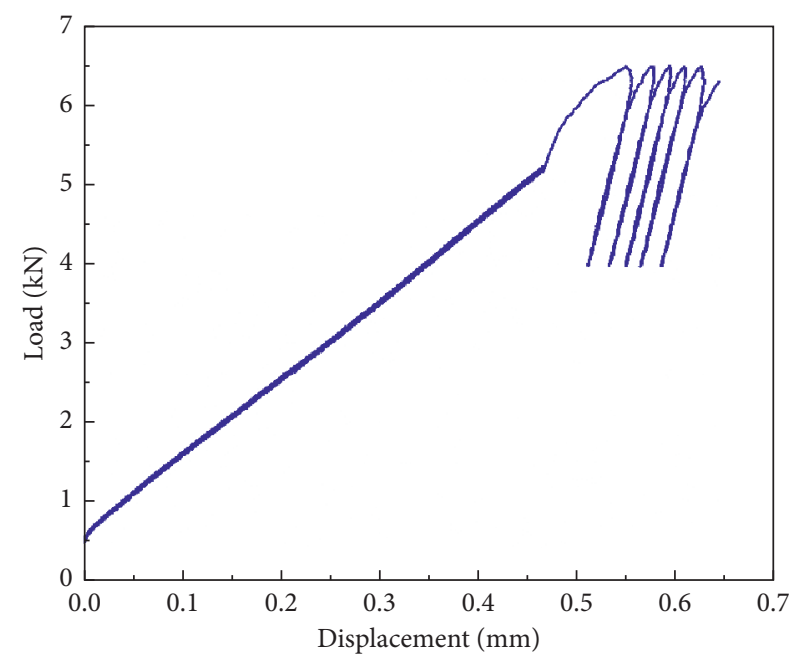

$-80 \%-1 \mathrm{~Hz}$

(c)

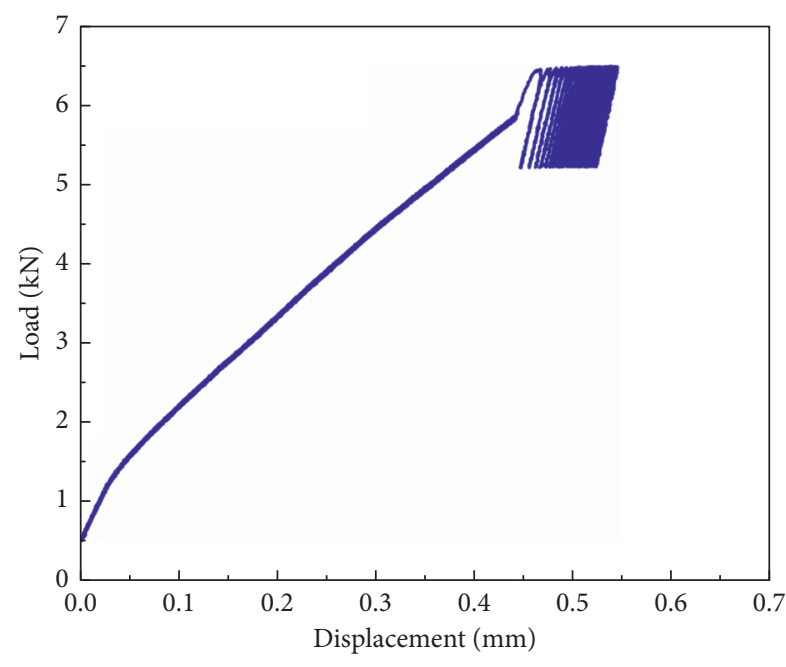

$-90 \%-2 \mathrm{~Hz}$

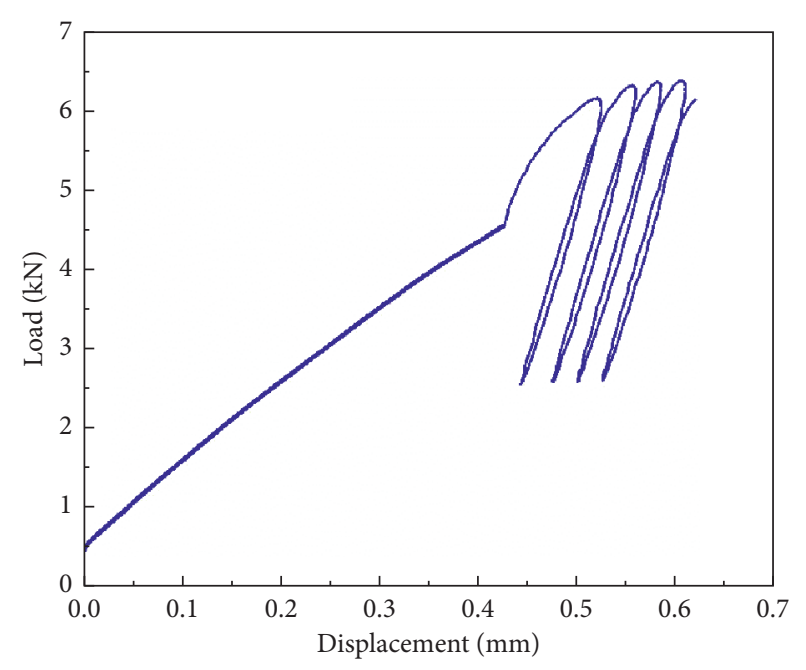

- $70 \%-10 \mathrm{~Hz}$

(b)

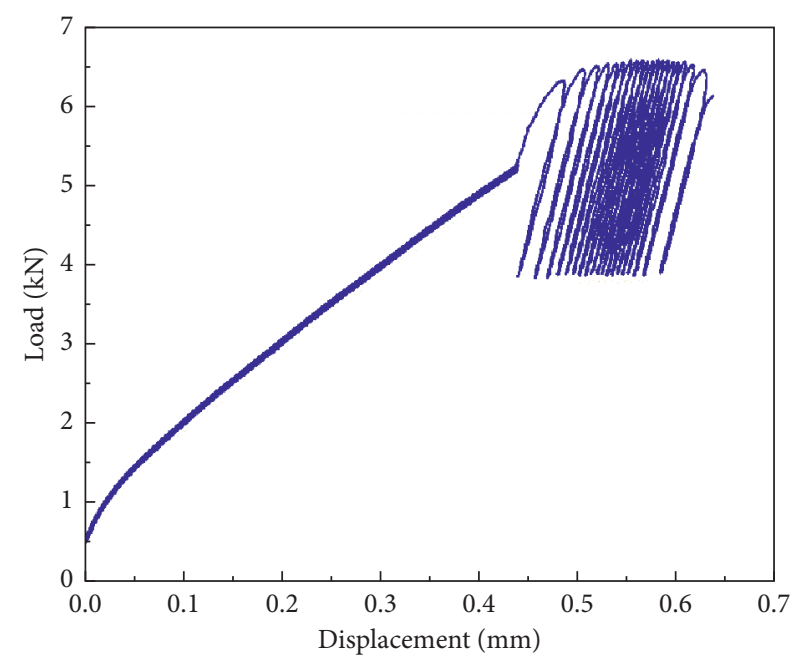

$-80 \%-10 \mathrm{~Hz}$

(d)

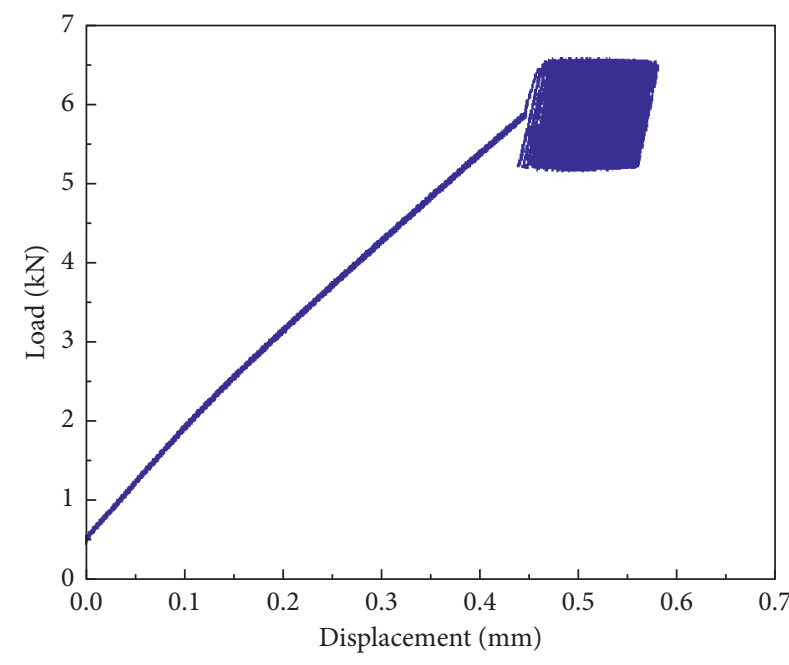

$-90 \%-10 \mathrm{~Hz}$

(e)

Figure 6: Typical load-displacement curves under the point load test. (a) $70 \%-1 \mathrm{~Hz}$; (b) $70 \%-10 \mathrm{~Hz}$; (c) $80 \%-1 \mathrm{~Hz}$; (d) $80 \%-10 \mathrm{~Hz}$; (e) $90 \%$ $2 \mathrm{~Hz}$; (f) $90 \%-10 \mathrm{~Hz}$ 
TABLE 2: The results under different prestatic loads and dynamic disturbances.

\begin{tabular}{|c|c|c|c|c|c|}
\hline Sample & $\begin{array}{c}F_{p}(\mathrm{kN}) \\
\left(F_{p} / F_{\max }\right) \\
\end{array}$ & $\begin{array}{l}F_{\min } \\
(\mathrm{kN})\end{array}$ & $\begin{array}{l}F_{\max } \\
(\mathrm{kN})\end{array}$ & $f(\mathrm{~Hz})$ & $\begin{array}{c}F \\
(\mathrm{kN})\end{array}$ \\
\hline $70 \%-1 \mathrm{~Hz}$ & \multirow{4}{*}{$4.56(70 \%)$} & \multirow{4}{*}{2.60} & \multirow{4}{*}{6.51} & 1 & 6.38 \\
\hline $70 \%-2 \mathrm{~Hz}$ & & & & 2 & 6.30 \\
\hline $70 \%-5 \mathrm{~Hz}$ & & & & 5 & 6.23 \\
\hline $\begin{array}{l}70 \%- \\
10 \mathrm{~Hz}\end{array}$ & & & & 10 & 6.14 \\
\hline $80 \%-1 \mathrm{~Hz}$ & \multirow{4}{*}{$5.21(80 \%)$} & \multirow{4}{*}{3.91} & \multirow{4}{*}{6.51} & 1 & 6.29 \\
\hline $80 \%-2 \mathrm{~Hz}$ & & & & 2 & 6.27 \\
\hline $80 \%-5 \mathrm{~Hz}$ & & & & 5 & 6.21 \\
\hline $\begin{array}{l}80 \%- \\
10 \mathrm{~Hz}\end{array}$ & & & & 10 & 6.11 \\
\hline $90 \%-1 \mathrm{~Hz}$ & \multirow{4}{*}{$5.86(90 \%)$} & \multirow{4}{*}{5.21} & \multirow{4}{*}{6.51} & 1 & 6.26 \\
\hline $90 \%-2 \mathrm{~Hz}$ & & & & 2 & 6.23 \\
\hline $90 \%-5 \mathrm{~Hz}$ & & & & 5 & 6.18 \\
\hline $\begin{array}{l}90 \%- \\
10 \mathrm{~Hz}\end{array}$ & & & & 10 & 6.03 \\
\hline
\end{tabular}

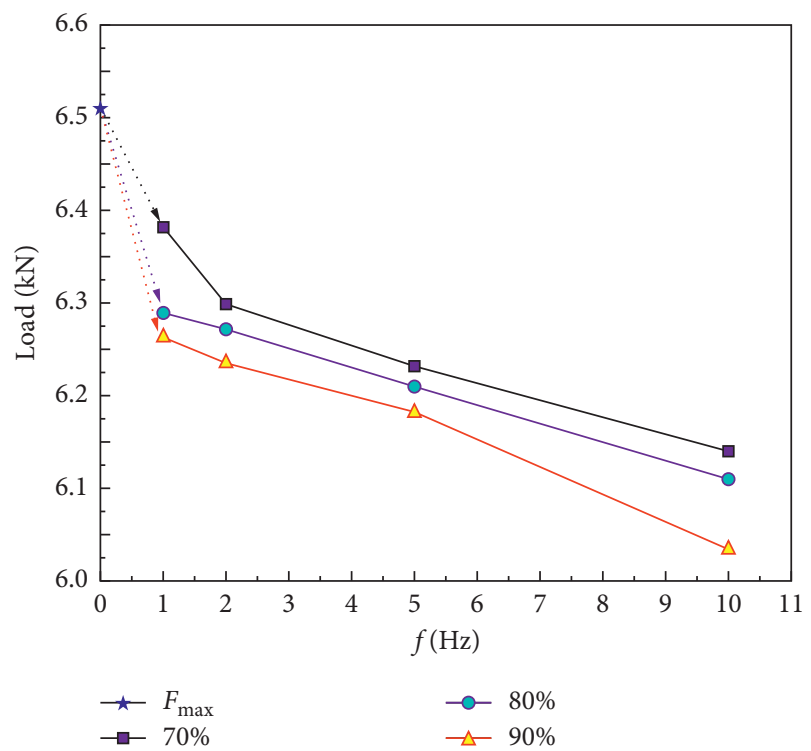

Figure 7: Failure load under the point load test.

TABLE 3: The point load strength of prestatically loaded marble subjected to dynamic disturbance.

\begin{tabular}{lccc}
\hline Sample & $F(\mathrm{kN})$ & $I_{s}^{d}(\mathrm{MPa})$ & PSWR $(\%)$ \\
\hline $70 \%-1 \mathrm{~Hz}$ & 6.38 & 1.99 & 2.39 \\
$70 \%-2 \mathrm{~Hz}$ & 6.30 & 1.96 & 3.65 \\
$70 \%-5 \mathrm{~Hz}$ & 6.23 & 1.95 & 4.30 \\
$70 \%-10 \mathrm{~Hz}$ & 6.14 & 1.91 & 6.20 \\
\hline $80 \%-1 \mathrm{~Hz}$ & 6.29 & 1.96 & 3.57 \\
$80 \%-2 \mathrm{~Hz}$ & 6.27 & 1.95 & 4.07 \\
$80 \%-5 \mathrm{~Hz}$ & 6.21 & 1.93 & 4.98 \\
$80 \%-10 \mathrm{~Hz}$ & 6.11 & 1.90 & 6.51 \\
\hline $90 \%-1 \mathrm{~Hz}$ & 6.26 & 1.95 & 4.32 \\
$90 \%-2 \mathrm{~Hz}$ & 6.23 & 1.94 & 4.71 \\
$90 \%-5 \mathrm{~Hz}$ & 6.18 & 1.92 & 5.71 \\
$90 \%-10 \mathrm{~Hz}$ & 6.03 & 1.87 & 8.00 \\
\hline
\end{tabular}

dynamic disturbance load, the point load strength has a significant strength weakening effect, which is attributed to the corresponding $F_{P}$ and $f$ (as illustrated in Figures 8 and 9). Moreover, this point load strength is obviously different from the mechanical properties of pure static point load strength. Obviously, the point load strength weakening degree depends on $F_{P}$ and $f$. Furthermore, within the same $f$, the greater the $F_{P}$, the more significant the point load strength weakening effect (as illustrated in Figure 8). Similarly, the test results further prove that, in the process of strength weakening, $F_{P}$ is dominant and determines its weakening level. At the same time, the test results also demonstrate that $f$ can promote the strength weakening process based on $F_{P}$, and $f$ also affects the weakening degree. In summary, the point load strength weakening process occurs under the combined action of $F_{P}$ and $f$. Only when $F_{P}$ reaches a certain degree, $f$ can induce obvious strength weakening (Figure 8). Similarly, only when $f$ reaches a certain degree, $F_{P}$ can promote the weakening process (Figure 9). However, in the whole strength weakening mechanism, the $F_{P}$ dominates and determines the weakening level, while the dynamic disturbance further induces the weakening process and $f$ affects the degree of weakening.

In this paper, the influence of the unloading process on rock strength is not considered. Our previous research shows that unloading can also weaken the rock strength $[30,31]$. In the future, we will study the failure characteristics of rock subjected to dynamic disturbance after unloading, and we have started to study the rock subjected to lowfrequency or impact dynamic disturbance after unloading.

3.5. Discussion on the Strength Weakening Mechanism under Tension Failure. After the deep rock engineering excavation, the surrounding rock has obvious strength weakening effects [30, 31]. Moreover, the sidewall of the tunnel often has obvious tensile failure [32], and the point load test is a typical tensile failure process. The point load failure mode of the sample subjected to the coupled static-dynamic loading conditions is basically similar to the static load, and both are obvious tensile failure modes (as shown in Figure 10). Comparison of the point load strength under the traditional static loading and the point load test under the coupled static-dynamic loading shows that the point load strength has obvious strength weakening effect. The existing literature has also confirmed that the tensile strength of rock shows obvious strength weakening effect under the coupled staticdynamic loading [32]. Gong et al. [32] carried out a Brazilian disk (BD) test on prestatically loaded BD samples subjected to low-frequency dynamic disturbance, and systematically analyzed the characteristics and mechanism of tensile strength changes, and the main conclusions are shown in Figure 11. The tensile strength of the $\mathrm{BD}$ sample under the pure static state is $4.89 \mathrm{MPa}$, but when $F_{P}$ is $90 \%$ under the coupled static-dynamic loading, the tensile strength decreases with $f$ until it reaches $4.32 \mathrm{MPa}$ at $f=50 \mathrm{~Hz}$, showing obvious strength weakening effect. A similar trend can also be observed when $F_{P}$ is $80 \%$. In the process of tensile strength weakening, $F_{P}$ still dominates the weakening level, 


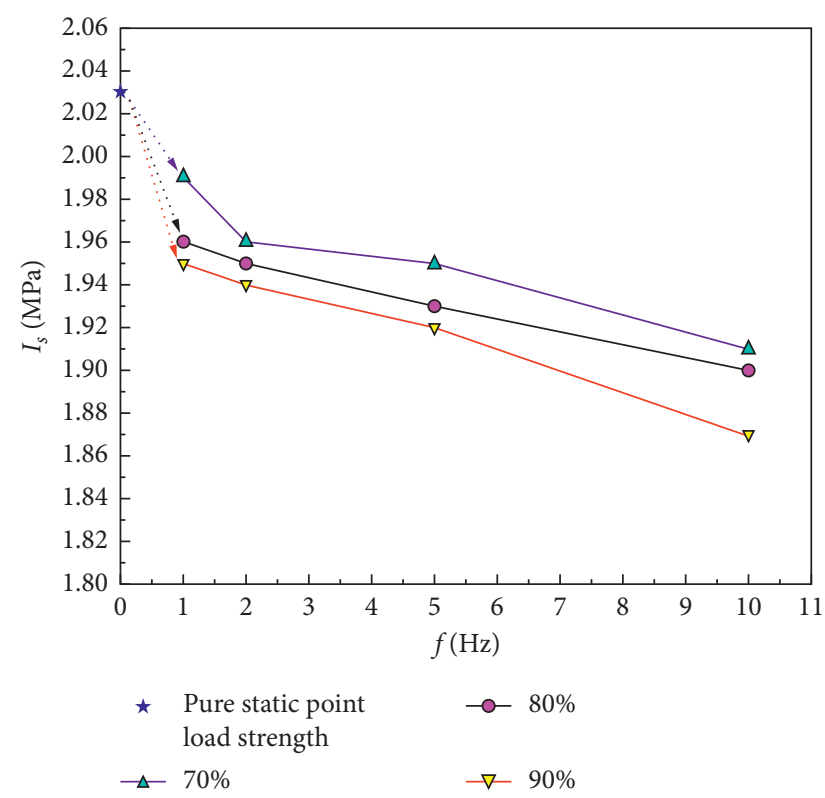

(a)

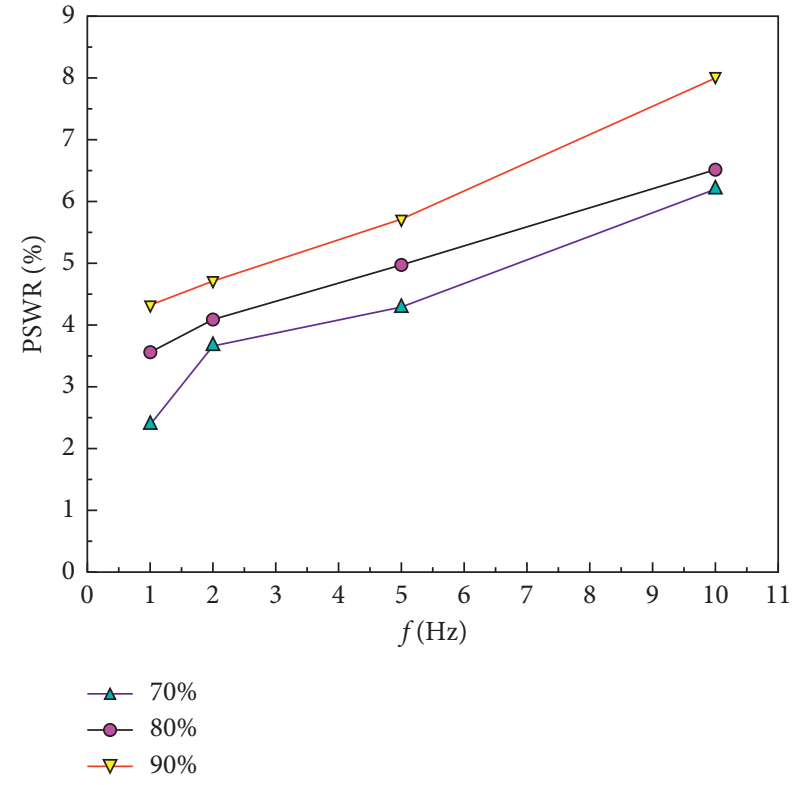

(b)

Figure 8: The point load strength and the corresponding weakening rate change trend with the disturbance frequency. (a) Point load strength. (b) PSWR.

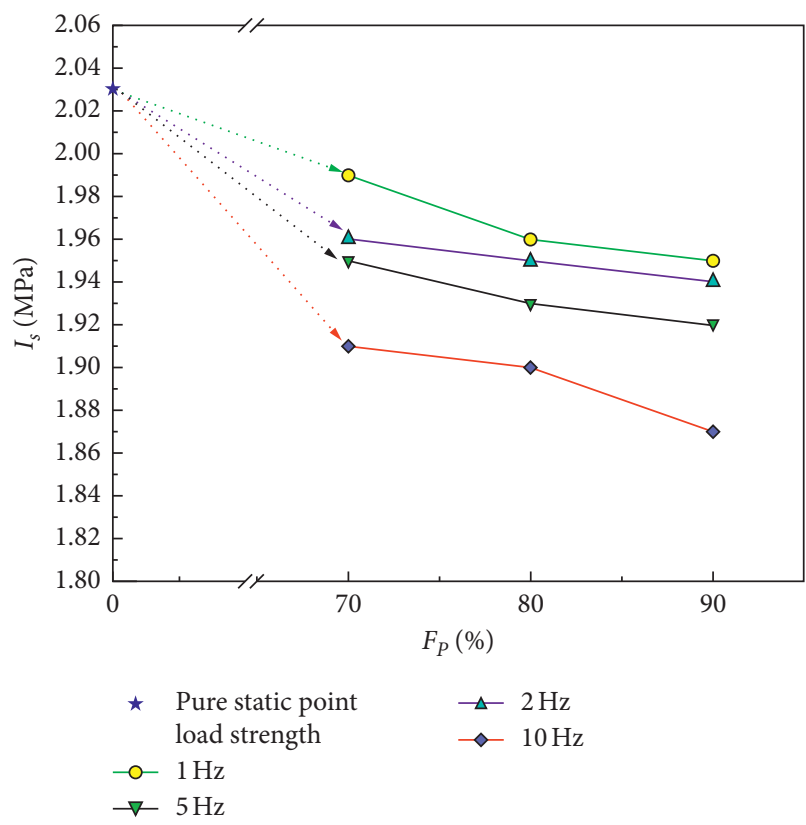

(a)

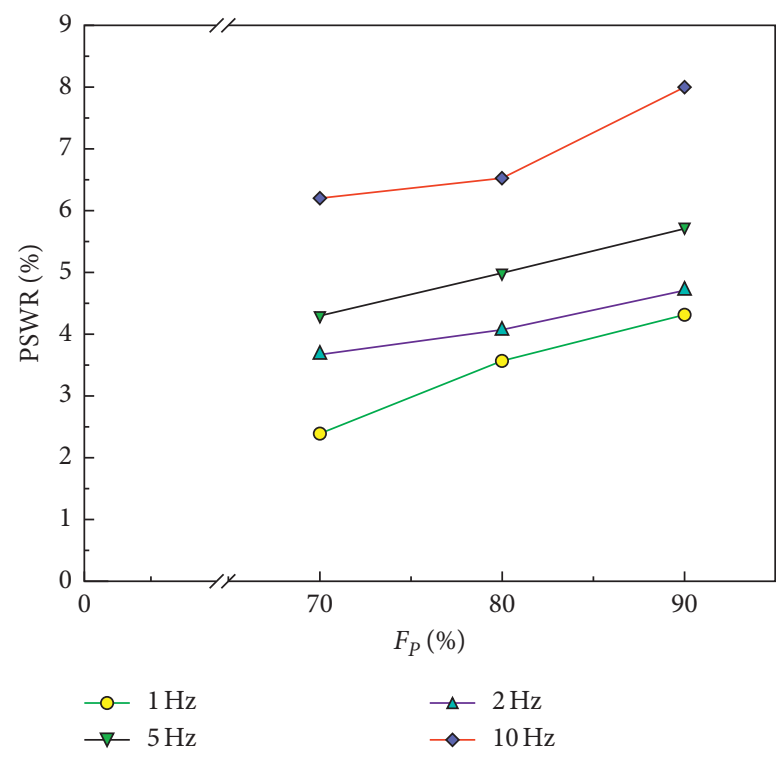

(b)

FIGURE 9: The point load strength and the corresponding weakening rate change trend with the prestatic load level. (a) Point load strength. (b) PSWR.

while the dynamic disturbance induces strength weakening and $f$ determines the weakening degree. This is consistent with the point load strength weakening mechanism.

In light of the comparison indicated above, the prestatic load rock subjected to low-frequency dynamic disturbance under the point load test or Brazilian disc test shows that the rock strength (point load strength and tensile strength) shows obvious strength weakening effect during the rock failure process. Moreover, in the process of rock strength weakening, $F_{P}$ dominates the strength weakening level and $f$ affects the degree of weakening. This conclusion also shows that the strength weakening mechanism is the same whether 


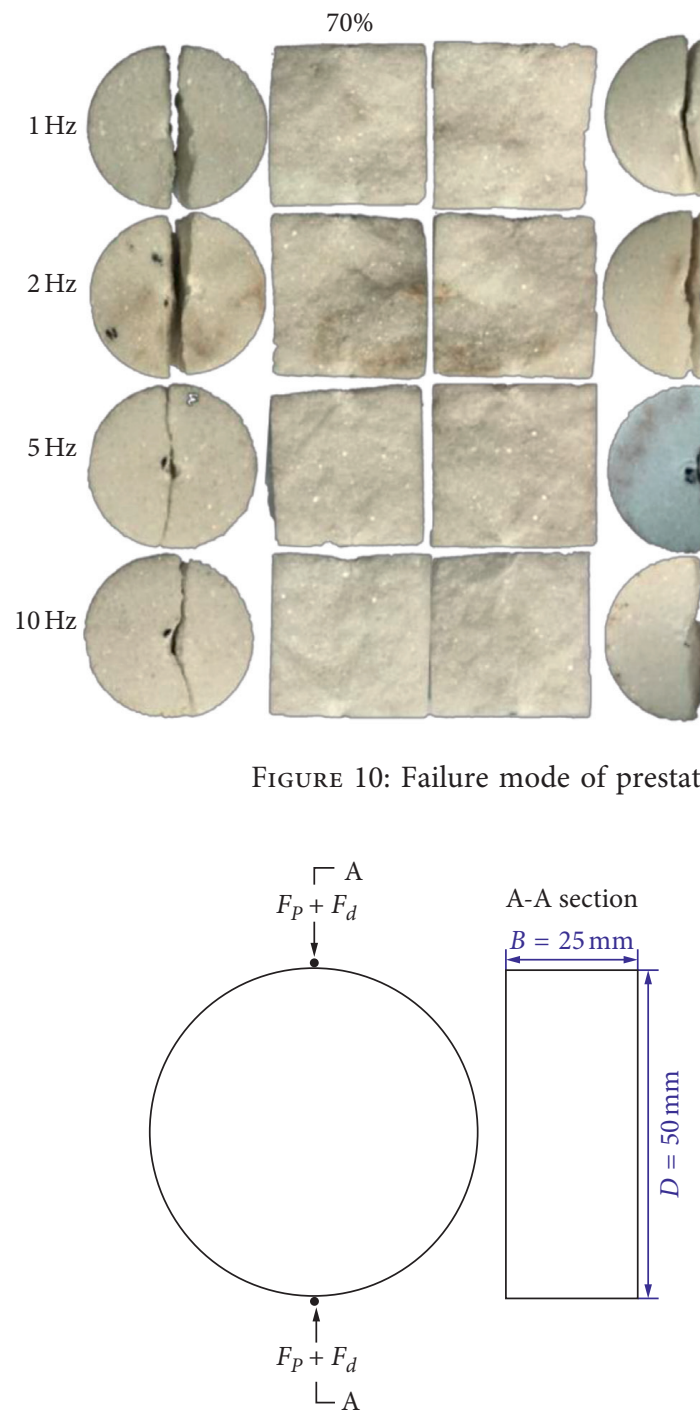

(a)

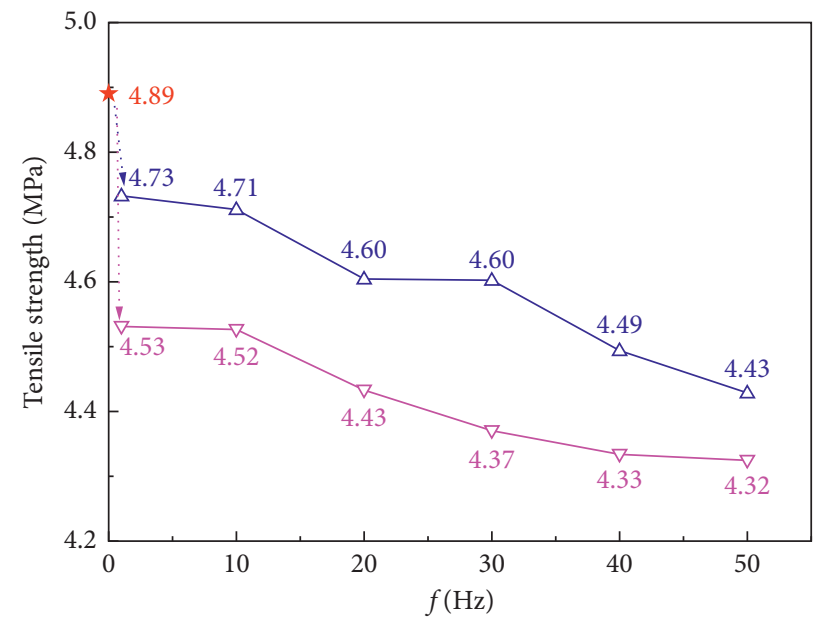

$\star-$ Pure static tensile strength
$-\triangle 80 \%$

$\rightarrow-90 \%$

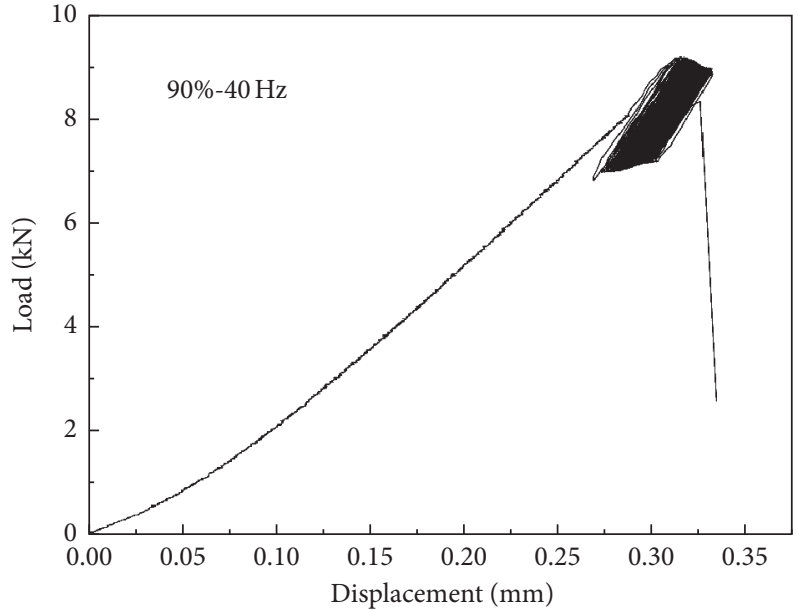

(b)

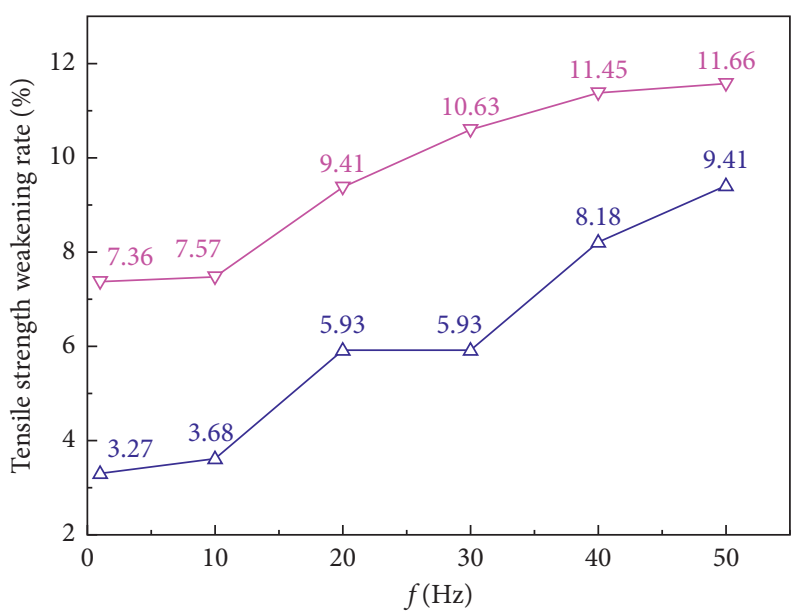

$\triangle 80 \%$

$\rightarrow-90 \%$

(c)

(d)

FIgUre 11: Test results of BD samples. (a) Sample size. (b) Typical load-displacement curve [32]. (c) Variation characteristics of tensile strength with disturbance frequency. (d) Variation characteristics of tensile strength weakening rate with disturbance frequency. 
the loading mode is the point load test or the Brazilian disc test during the tensile failure process, that is, the strength weakening process is not necessarily related to the loading mode, only related to $F_{P}$ and $f$.

\section{Conclusions}

A series of point load tests were conducted on the prestatically loaded marble sample subjected to low-frequency dynamic disturbance, and several important conclusions were obtained as follows:

(1) The point strength of the point load test under the prestatically loaded marble sample subjected to lowfrequency dynamic disturbance loading tests is significantly lower than that under pure static loading, showing a significant strength weakening effect.

(2) As long as $F_{P}$ and $f$ exceed a certain value, the strength weakening effect decreases significantly with the increase of $f$ and $F_{P}$.

(3) During the whole point load strength weakening process, $F_{P}$ dominates and determines the weakening level, while $f$ affects the weakening degree.

(4) Both the point load test and the Brazilian disc test of the deep high prestatically loaded rock subjected to low-frequency dynamic disturbance show obvious strength weakening effects, and it is strongly proved that the strength weakening process is only related to $F_{P}$ and $f$, while the loading mode is basically irrelevant.

\section{Data Availability}

All data used to support the findings of this study are included within the article.

\section{Conflicts of Interest}

The authors declare that there are no conflicts of interest regarding the publication of this article.

\section{Acknowledgments}

This work was supported by the National Natural Science Foundation of China (grant no. 42077244) and the Fundamental Research Funds for the Central Universities of Southeast University (grant no. 2242021R10080).

\section{References}

[1] W. D. Ortlepp, "The behaviour of tunnels at great depth under large static and dynamic pressures," Tunnelling and Underground Space Technology, vol. 16, no. 1, pp. 41-48, 2001.

[2] X. B. Li, Z. L. Zhou, T. S. Lok, L. Hong, and T. B. Yin, "Innovative testing technique of rock subjected to coupled static and dynamic loads," International Journal of Rock Mechanics and Mining Sciences, vol. 45, no. 5, pp. 739-748, 2008.

[3] S. Zhong, Q. Jiang, C. Liu et al., "In-site core disking phenomenon and break mechanism of hard marble: investigation in $2400 \mathrm{~m}$ deep-buried underground laboratory," Journal of Central South University of Technology, vol. 27, pp. 2899-2913, 2020.
[4] J. Zhao, Y. X. Zhou, A. M. Hefny et al., "Rock dynamics research related to cavern development for ammunition storage," Tunnelling and Underground Space Technology, vol. 14, no. 4, pp. 513-526, 2001.

[5] R. Q. Huang and X. N. Wang, "Analysis of dynamic disturbance on rock burst," Bulletin of Engineering Geology and the Environment, vol. 57, no. 3, pp. 281-284, 1999.

[6] X. B. Li, F. Q. Gong, M. Tao et al., "Failure mechanism and coupled static-dynamic loading theory in deep hard rock mining: a review," Journal of Rock Mechanics and Geotechnical Engineering, vol. 9, no. 4, pp. 767-782, 2017.

[7] Q. B. Zhang and J. Zhao, "A review of dynamic experimental techniques and mechanical behaviour of rock materials," Rock Mechanics and Rock Engineering, vol. 47, no. 4, pp. 1411-1478, 2014.

[8] K. Liu, Q. B. Zhang, G. Wu, J. C. Li, and J. Zhao, "Dynamic mechanical and fracture behaviour of sandstone under multiaxial loads using a triaxial hopkinson bar," Rock Mechanics and Rock Engineering, vol. 52, no. 7, pp. 2175-2195, 2019.

[9] V. Ernesto, T. Alan, and W. Christopher, "Probabilistic estimate of rock mass static and dynamic demands for underground excavation stabilization," Journal of Rock Mechanics and Geotechnical Engineering, vol. 11, no. 3, pp. 45-57, 2019.

[10] M. Z. Gao, J. G. Zhang, S. W. Li, M. Wang, Y. W. Wang, and P. F. Cui, "Calculating changes in fractal dimension of surface cracks to quantify how the dynamic loading rate affects rock failure in deep mining," Journal of Central South University, vol. 27, no. 10, pp. 3013-3024, 2020.

[11] R. G. Vaneghi, B. Ferdosi, A. D. Okoth et al., "Strength degradation of sandstone and granodiorite under uniaxial cyclic loading," Journal of Rock Mechanics and Geotechnical Engineering, vol. 10, no. 1, pp. 117-126, 2018.

[12] R. G. Vaneghi, K. Thoeni, A. V. Dyskin et al., "Strength and damage response of sandstone and granodiorite under different loading conditions of multistage uniaxial cyclic compression," International Journal of Geomechanics, vol. 20, no. 9, Article ID 04020159, 2020.

[13] F. Q. Gong, X. B. Li, X. L. Liu et al., "Experimental study of dynamic characteristics of sandstone under one-dimensional coupled static and dynamic loads," Chinese Journal of Rock Mechanics and Engineering, vol. 29, no. 10, pp. 2076-2085, 2010.

[14] Z. L. Zhou, X. Cai, X. B. Li, W. Z. Cao, and X. M. Du, "Dynamic response and energy evolution of sandstone under coupled static-dynamic compression: insights from experimental study into deep rock engineering applications," Rock Mechanics and Rock Engineering, vol. 53, no. 3, pp. 1305-1331, 2020.

[15] W. C. Zhu, Y. Bai, X. B. Li, and L. L. Niu, "Numerical simulation on rock failure under combined static and dynamic loading during SHPB tests," International Journal of Impact Engineering, vol. 49, pp. 142-157, 2012.

[16] K. Peng, Z. P. Liu, Q. L. Zou et al., "Static and dynamic mechanical properties of granite from various burial depths," Rock Mechanics and Rock Engineering, vol. 52, pp. 3545-3566, 2019.

[17] Z. Q. Yin, X. B. Li, J. F. Jin, X. Q. He, and K. Du, "Failure characteristics of high stress rock induced by impact disturbance under confining pressure unloading," Transactions of Nonferrous Metals Society of China, vol. 22, no. 1, pp. 175-184, 2012. 
[18] S. S. Ma, W. Z. Chen, and W. S. Zhao, "Effects of axial static stress and confining pressure on the dynamic compressive behaviours of granite," European Journal of Environmental and Civil Engineering, vol. 25, no. 5, 2019.

[19] K. Liu, J. Zhao, G. Wu, A. Maksimenko, A. Haque, and Q. B. Zhang, "Dynamic strength and failure modes of sandstone under biaxial compression," International Journal of Rock Mechanics and Mining Sciences, vol. 128, Article ID 104260, 2020.

[20] W. Yuan, X. Wang, and X. B. Wang, "Numerical investigation on effect of confining pressure on the dynamic deformation of sandstone," European Journal of Environmental and Civil Engineering, 2020.

[21] W. R. Hu, K. Liu, D. O. Potyondy, and Q. B. Zhang, "3D continuum-discrete coupled modelling of triaxial Hopkinson bar tests on rock under multiaxial static-dynamic loads," International Journal of Rock Mechanics and Mining Sciences, vol. 134, Article ID 104448, 2020.

[22] W. C. Zhu and C. A. Tang, "Numerical simulation of Brazilian disk rock failure under static and dynamic loading," International Journal of Rock Mechanics and Mining Sciences, vol. 43, no. 2, pp. 236-252, 2006.

[23] B. B. Wu, R. Chen, and K. W. Xia, "Dynamic tensile failure of rocks under static pre-tension," International Journal of Rock Mechanics and Mining Sciences, vol. 80, pp. 12-18, 2015.

[24] W. Yao, K. W. Xia, and A. K. Jha, "Experimental study of dynamic bending failure of Laurentian granite: loading rate and pre-load effects," Canadian Geotechnical Journal, vol. 56, pp. 228-235, 2018.

[25] R. Chen, K. Li, K. Xia, Y. Lin, W. Yao, and F. Lu, "Dynamic fracture properties of rocks subjected to static pre-load using notched semi-circular bend method," Rock Mechanics and Rock Engineering, vol. 49, no. 10, pp. 3865-3872, 2016.

[26] D. D. Shi and X. D. Chen, "Flexural tensile fracture behavior of pervious concrete under static preloading," Journal of Materials in Civil Engineering, vol. 30, no. 11, Article ID 06018015, 2018

[27] G. S. Su, L. H. Hu, X. T. Feng et al., "True triaxial experimental study of rockburst process under low frequency cyclic disturbance load combined with static load," Chinese Journal of Rock Mechanics and Engineering, vol. 35, no. 7, pp. 1309-1322, 2016.

[28] W. X. Wu, F. Q. Gong, and W. M. Yang, "Experimental simulation study of spalling in deep rectangular tunnel with plastic fine grain marble," Tunnelling and Underground Space Technology, vol. 98, Article ID 103319, 2020.

[29] International Society for Rock Mechanics (ISRM), "Suggested method for determining point load strength: ISRM common testing methods," International Journal of Rock Mechanics and Mining Sciences \& Geomechanics Abstracts, vol. 22, no. 4, p. 112, 1985.

[30] X. F. Si and F. Q. Gong, "Strength-weakening effect and sheartension failure mode transformation mechanism of rockburst for fine-grained granite under triaxial unloading compression," International journal of rock mechanics and mining sciences, vol. 131, Article ID 104347, 2020.

[31] X. F. Si and F. Q. Gong, "Study on rockburst simulation tests and strength-weakening effect of circular tunnels under deep high stress and internal unloading conditions," Chinese Journal of Rock Mechanics and Engineering, vol. 40, pp. 1-14, 2021.

[32] F. Q. Gong, W. X. Wu, and L. Zhang, "Brazilian disc test study on tensile strength-weakening effect of high pre-loaded red sandstone under dynamic disturbance," Journal of Central South University, vol. 27, no. 10, pp. 2899-2913, 2020. 